Rhode Island College

Digital Commons @ RIC

\title{
Implementation and Evaluation of the Peg Pain Assessment Scale in a Primary Care Setting
}

Nancy L. Harritos

Follow this and additional works at: https://digitalcommons.ric.edu/etd

Part of the Nursing Commons

\section{Recommended Citation}

Harritos, Nancy L., "Implementation and Evaluation of the Peg Pain Assessment Scale in a Primary Care Setting" (2020). Master's Theses, Dissertations, Graduate Research and Major Papers Overview. 394.

https://digitalcommons.ric.edu/etd/394

This Thesis is brought to you for free and open access by the Master's Theses, Dissertations, Graduate Research and Major Papers at Digital Commons @ RIC. It has been accepted for inclusion in Master's Theses, Dissertations, Graduate Research and Major Papers Overview by an authorized administrator of Digital Commons @ RIC. For more information, please contact digitalcommons@ric.edu. 



\title{
IMPLEMENTATION AND EVALUATION OF THE PEG PAIN ASSESSMENTSCALE IN A PRIMARY CARE SETTING
}

\author{
A Scholarly Project Submitted in Partial Fulfillment of \\ The Requirements for the Degree of \\ Doctor of Nursing Practice \\ in \\ The School of Nursing \\ Rhode Island College \\ June 6, 2020 \\ by
}

Nancy L. Harritos

Approved:

Marie A. Wilks, DNP, RN-BC 


\section{IMPLEMENTATION AND EVALUATION OF THE PEG PAIN ASSESSMENT SCALE IN A PRIMARY CARE SETTING}

A Scholarly Project Submitted in Partial Fulfillment of

The Requirements for the Degree of

Doctor of Nursing Practice

in

The School of Nursing

Rhode Island College

June 06, 2020

by

Nancy L. Harritos 


\section{Acknowledgements}

I would like to express my gratitude to the faculty and staff members of the Rhode Island College School of Nursing for their support. I am particularly thankful to my project advisor, Dr. Marie Wilks and DNP advisor Justin DiLibero, for their guidance and dedication to the success of this project. I am thankful for the support of Dr. Linda Dame as content expert, Dr. Ron Pitt as biostatistical analysis mentor, and Dr. Mark Schleinitz of Rhode Island Hospital as organizational mentor for this project. 


\begin{abstract}
Background: Inadequate pain assessment is a significant problem and a key barrier to appropriate pain management. While pain assessment has become a standard, the practice of assessing pain as the "fifth vital sign" has resulted in perfunctory recordings that are less meaningful than intended. Unidimensional pain rating scales such as the numeric rating scale (NRS) are quick to administer and provide an assessment of pain severity but lack depth and are more useful for evaluating acute pain rather than chronic pain (Younger, 2005; Goldsmith, 2018). A multidimensional pain assessment tool, which assesses pain intensity as well as impact on functional status and quality of life would have greater relevance in use for chronic pain management.
\end{abstract}

Purpose/Specific Aims: This project evaluates the feasibility, effectiveness, and impact of using a multidimensional pain assessment tool in place of the currently used unidimensional NRS to assess chronic pain in a primary care setting. A multidimensional pain assessment tool that evaluates not only the severity of pain, but also the impact of pain on quality and functioning could improve patient care and pain management.

Methods: Twenty-five patients with a diagnosis of chronic pain were evaluated during a routine appointment at their primary care practice. Each participant was screened with the Numeric Rating Scale (NRS) per usual practice at this setting. The nurse practitioner (NP) then used the Pain, Enjoyment of life, and General Activity (PEG) scale to assess each participant. A retrospective review of the electronic health record (EHR) identified the NRS scores and the pain management modalities from two visits prior to the use of the PEG assessment. A comparative analysis was done to look at similarities and 
differences between the two pain scales, as well as to compare the pain management modalities resultant from both measures.

Results: There was a visible, but not significant, increase in PEG scores with higher NRS scores with a correlation coefficient of $0.22892610, t=1.12784221$ which was not significant. There was some correlation between the NRS and the "P" of the PEG score, which assesses pain intensity, although it also was not significant. The PEG scale had greater variability in scores compared to the NRS, which is not unexpected as it is a multidimensional rather than a unidimensional scale. Use of the PEG scale was associated with an increase in multi-modal non-pharmacologic pain management recommendations in this patient population that at baseline had largely been treated with pharmacologic measures.

Conclusion: The use of the PEG tool provided a more comprehensive assessment than did the NRS unidimensional pain scale, which focuses on pain intensity alone. Chronic pain assessment that includes an evaluation of functional impact and quality of life provides a richer picture of the individual's status. In comparison to the NRS, the use of the PEG assessment resulted in broader, more individualized pain management recommendations that focused more on non-pharmacologic modalities.

Key Words: chronic pain; pain assessment tools; pain management; PEG scale, multidimensional pain scale, functional pain assessment 


\section{Table of Contents}

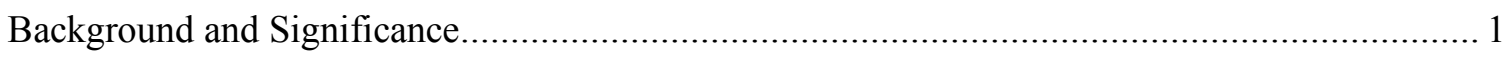

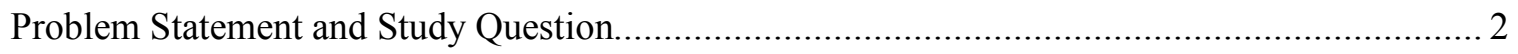

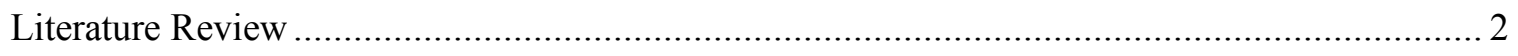

Organizational Assessment/Local Problem ..................................................................... 6

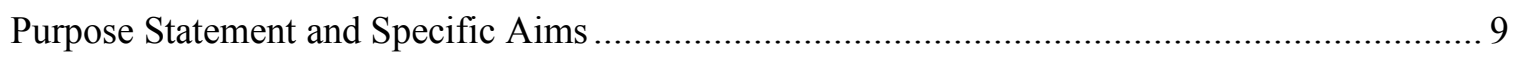

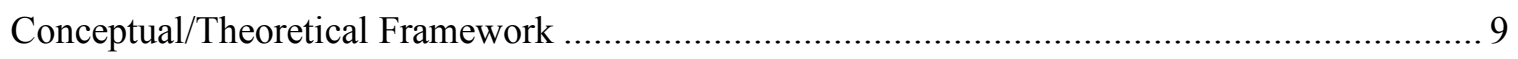

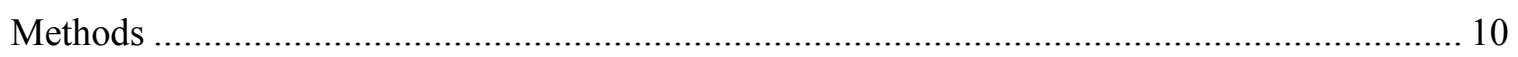

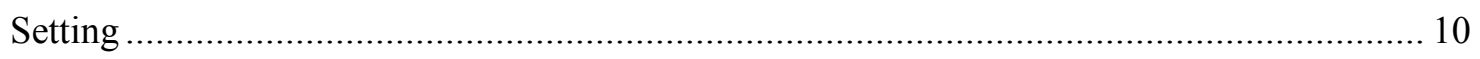

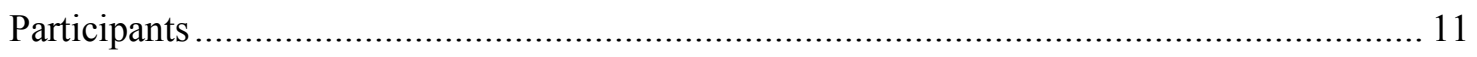

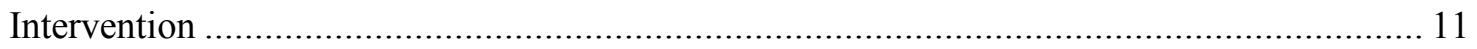

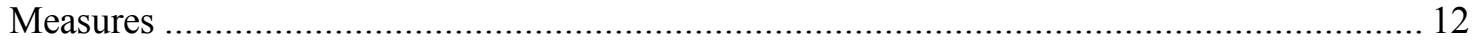

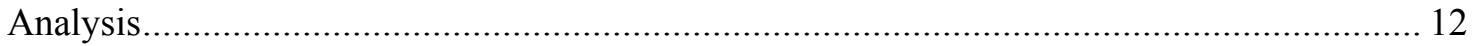

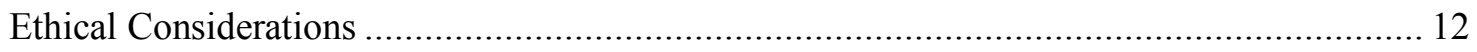

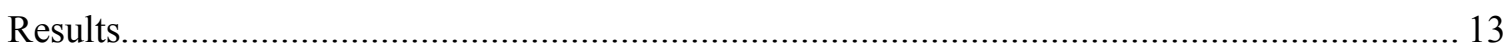

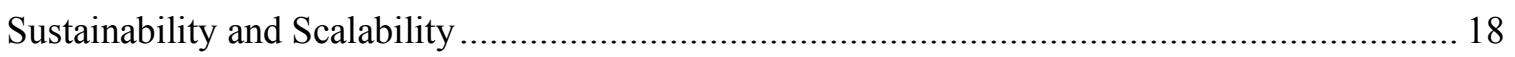

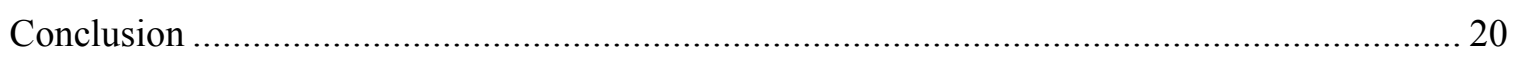

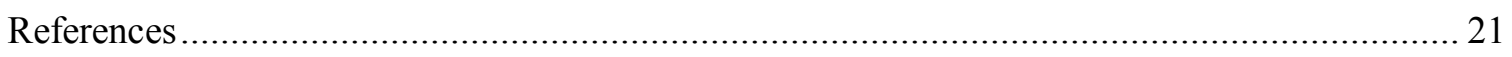

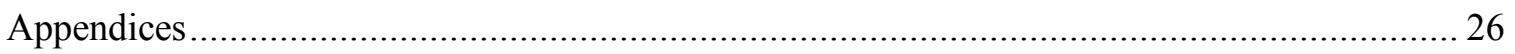


IMPLEMENTATION AND EVALUATION OF THE PEG PAIN ASSESSMENT

SCALE IN A PRIMARY CARE SETTING

Background and Significance

According to a 2016 survey by the National Health Interview Survey conducted by the U.S. Department of Health and Human Services, approximately 50 million Americans have significant chronic pain (Dahlhamer et al., 2018). Although there is no agreed upon definition of chronic pain, it is commonly referred to as an unpleasant sense of discomfort that is without biological value, lasting longer than the typical healing time, not responsive to specific treatments or remedies, and of a duration greater than 3 months (Katz, Rosenbloom, \& Fashler, 2015). Unlike acute pain, which is considered a normal response to a specific condition, is self-limiting and is usually treatable, chronic pain serves no adaptive purpose and is less easily defined. The International Association Study of Pain provides a taxonomy system that defines and classifies chronic pain into more than 30 categories (Teede et al., 2019). This attests to the complexity of chronic pain, as well as the inherent difficulties in pain assessment.

Of the 50 million Americans having chronic pain, 20 million or $8 \%$ of the U.S. adult population have high impact pain. This is defined as pain that frequently and significantly interferes with life or work activities (Dahlmaher et al., 2018). Chronic pain is associated with increased mortality, independent of socio-demographic factors (Torrance et al., 2011). Over the past two decades, the impact of pain and the inadequacies of the health care system in alleviating pain have been in the forefront. In a landmark 2001 report, The Joint Commission (TJC), formerly known as the Joint Commission on Accreditation of Healthcare Organizations (JCAHO), which accredits 
and certifies nearly 21,000 health care organizations in the United States, called for national standards in pain assessment and management. These standards included the requirement that health care facilities "recognize the right of patients to appropriate assessment and management of pain; to record the assessment in a way that facilitates regular reassessment and follow-up..." (Phillips, 2010, Standard PC. 6.10), While these standards call for the assessment and management of patients' pain, they do not require a specific assessment tool or specific timing for reassessment (Joint Commission Perspectives, 2014). The Center for Disease Control (CDC) and TJC both note that while unidimensional numeric pain scales can be appropriate and helpful as part of an initial assessment, they are usually inadequate on their own. Current guidelines advocate for the use of a functional assessment to improve the efficacy and safety of chronic pain management (CDC, 2016; Moore, Anderson, \& Dorflinger, 2016).

\section{Problem Statement and Study Question}

Given the prevalence and significance of high impact chronic pain, the impetus is on health care providers to utilize effective assessment tools in order to effectively guide the implementation of patient-centered pain management. How would the use of a multidimensional pain assessment tool compare to a unidimensional assessment tool in evaluating and managing chronic pain in a primary care setting?

\section{Literature Review}

More than $50 \%$ of Americans who report chronic pain receive pain-related care in the primary care setting (Anderson, Wang, \& Zlateva, 2012). Despite many years of multiple national initiatives, improvements in chronic pain management have been limited (Reuben et al., 2015). An estimated 40-60\% of those affected by chronic pain report 
inadequate pain management (Busse et al.,2017). Effective pain management is dependent upon an appropriate and comprehensive pain assessment.

Pain assessment ratings or scores, based upon established pain scales or instruments, are the basis of pain management. Pain is subjective, therefore self-report is widely accepted to be "the golden rule." In 1968, Mary Margo McCaffery, a nursing pioneer in the research, education, and care of people with pain, stated "Pain is whatever the experiencing person says it is, existing whenever he says it does" (McCaffrey, 1968). This definition of pain continues to be accepted and used in both medicine and nursing today. Therefore, a report from the patient is the single most reliable indicator of pain.

The most frequently used and well-studied unidimensional pain scales include the visual analog scale (VAS) and the numeric rating scale (NRS). Both of these scales consist of scores from 0 to 10 which are listed from left to right, with 0 (no pain) being on the far left and 10 (the worst pain imaginable) being on the far right. An alternative to the VAS and NRS scales is the FACES rating scale. The FACES scale is a useful option for young children or those who cannot speak English fluently (Jensen, 2003; Younger, 2009). These scales are simple, reliable, and valid, but have largely been developed and utilized in the acute care setting and therefore have limited application to chronic pain assessment.

Several studies have found that unidimensional pain scales, such as the NRS, are inconsistently used and provide minimal guidance in clinical care (Buckenmaier et al., 2013). Chronic pain is a complex, individualized experience, which calls for the use of a multidimensional pain assessment tool (Anderson, Wang, \& Zlateva, 2012). These instruments typically measure several dimensions of pain, including pain intensity, 
quality, interference with functioning, and effects on general quality of life. The McGill Pain Questionnaire is a 20-item, well-validated tool, which has pain ratings using sensory terms, such as sharp or stabbing, and affective terms, such as sickening. The Brief Pain Inventory (BPI) is a comprehensive multi-dimensional pain assessment that assesses two broad pain domains: 1) the sensory intensity of pain, and 2) the degree to which pain interferes with different areas of life. The Brief Pain Inventory (BPI) and the McGill Pain Questionnaire have a "short-form" which are 17 and 15 questions respectively, taking an estimated fifteen minutes to complete (Younger, 2009).

The Pain, Enjoyment of life, and General Activity (PEG) assessment tool (Figure 1) is a three-item scale based upon the BPI. This is a brief, yet multidimensional pain measure, which assess pain intensity $(\mathrm{P})$, interference with enjoyment of life $(\mathrm{E})$, and interference with general activity $(\mathrm{G})$. Each item is rated zero to ten and is based on “average in the past week." In a longitudinal study of 500 primary care patients with chronic pain and a cross-sectional study of 646 ambulatory care veterans, the PEG was found to have reliability, construct validity $(\mathrm{r}=0.77-0.95)$, and responsiveness compared to the BPI (Krebs et al., 2009). The PEG has also been found to be more responsive than the 36-Item Short Form Health Survey (SF-36), a detailed bodily pain scale, when used in outcome assessment to evaluate improvements in pain (Krebs et al., 2010).

Figure 1. PEG: A Three-Item Scale Assessing Pain Intensity and Interference 


\section{What number best describes your pain on average in the past week:}

\begin{tabular}{lllllllllll}
0 & 1 & 2 & 3 & 4 & 5 & 6 & 7 & 8 & 9 & 10 \\
\hline No pain & & & & & & & & & $\begin{array}{l}\text { Pain as bad as } \\
\text { you can imagine }\end{array}$
\end{tabular}

2. What number best describes how, during the past week, pain has interfered with your enjoyment of life?

\begin{tabular}{lllllllllll}
0 & 1 & 2 & 3 & 4 & 5 & 6 & 7 & 8 & 9 & 10 \\
\hline $\begin{array}{l}\text { Does not } \\
\text { interfere }\end{array}$ & & & & & & & & & $\begin{array}{l}\text { Completely } \\
\text { interferes }\end{array}$
\end{tabular}

\section{What number best describes how, during the past week, pain has interfered} with your general activity?

\begin{tabular}{lcccccccccc}
0 & 1 & 2 & 3 & 4 & 5 & 6 & 7 & 8 & 9 & 10 \\
\hline $\begin{array}{l}\text { Does not } \\
\text { interfere }\end{array}$ & & & & & & & & & $\begin{array}{l}\text { Completely } \\
\text { interferes }\end{array}$
\end{tabular}

Figure 1 From Krebs et al., 2009.

A small but relevant quality improvement study using the PEG in a primary care practice found that use of the PEG was well-accepted. The findings included: 94\% provider adherence with documentation in the medical record. Fifty-six percent of providers reported increased conversations with patients about chronic pain and 38\% reported an improved understanding of the patient's pain and functional status with use of the PEG (Stevens, 2019).

The Center for Disease Control (CDC) 2018 guidelines for the management of chronic pain addresses patient-centered clinical practices, which includes conducting thorough assessments, considering all possible treatments, and evaluating outcomes.. The CDC specifically recommends use of the PEG in chronic pain management, particularly when considering opioid treatment, as well as to track outcomes (Dowell, Haegerich, \& Chou, 2016). According to the 2015 National Pain Strategy that was based upon a joint 
effort of the National Institutes of Health (NIH) and the Institute of Medicine (IOM), goals of treatments should include improvement in both pain relief and function, which is tied to quality of life (Lu, 2015). This report recommends the use of multimodal pain management strategies, including both non-pharmacologic and pharmacologic measures as a means to better manage pain and improve function ( $\mathrm{Lu}, 2015)$. The National Pain Strategy included a classification of pharmacologic and non-pharmacologic pain management modalities, also referred to as health care services for pain. These consist of the following categories: medications, professional services, procedures, and miscellaneous non-pharmacologic measures (Interagency Pain Research Coordinating Committee, 2016) (See Appendix C). A multidimensional pain assessment tool, such as the PEG scale, which includes functional status and quality of life measures would give the health care provider a more effective guide for pain management beyond pain intensity measures alone.

\section{Organizational Assessment/Local Problem}

Over the past two decades, the burden of chronic pain and the opioid epidemic have both raised significant concerns on the societal, political, and health care fronts, at both the local and national level. Despite standards and recommendations that call for pain assessment, the actual practice and application of pain assessment is highly variable. A survey of members of the American Pain Society found that while pain ratings were obtained during "All visits" by $43.2 \%$ and "Most of the time" by $21.1 \%$, many of the members reported that the pain ratings had "Minimal" impact on the care of their patients (Bačkonja \& Farrar, 2015). In a primary care practice study, $80 \%$ of the providers 
reported that functional assessments have value in treating patients with chronic pain, but only $20 \%$ reported using them regularly (Stevens, 2019).

The 2010 Patient Protection and Affordable Care Act required the Department of Health and Human Services (HHS) to enlist the Institute of Medicine (IOM) in order that pain be examined as a public health problem. In 2016, HHS released the National Pain Strategy, the federal government's first coordinated, evidence-based plan, to reduce the burden of chronic pain affecting millions of Americans. According to B. DeSalvo, M.D., M.P.H., M.Sc., HHS Acting Assistant Secretary for Health, “This report identifies the key steps we can take to improve how we prevent, assess and treat pain in this country" (Interagency Pain Research Coordinating Committee, 2016). According to the National Pain Strategy, assessment of chronic pain and goals of treatments must be identified, specifically to include improvement in both pain relief and function ((National Institutes of Health, 2019). This report specifically recommends the use of multimodal pain management strategies, including both non-pharmacologic and pharmacologic measures as a means to better manage pain and improve function, which is tied to quality of life (National Institutes of Health, 2019).

In 2016, the Center of Disease Control released the "Guidelines for Prescribing Opioids for Chronic Pain" which included the recommendations: to establish and measure goals for pain and function; to discuss benefits and risks of opioids, and to discuss the availability of non-opioid therapies with patients (Dowell, Haegerich, \& Chou, 2016). The CDC Guidelines for the Management of Chronic Pain addresses patient-centered clinical practices, which include conducting thorough assessments, considering all possible treatments, and evaluating outcomes (Centers for Disease 
Control and Prevention, 2016). The CDC specifically recommends use of the PEG in chronic pain management, particularly when considering opioid treatment, as well as to track outcomes (Dowell et al., 2016).

Locally, in 2018, the Rhode Island Department of Health released pain management regulations that included guidelines for pain assessment and regulations on the prescribing of controlled substances. The regulations include required documentation of a treatment plan for patients with chronic pain who are prescribed opioids for pain management. At minimum, this documentation is to include a baseline pain assessment, the objectives used to determine treatment success, an assessment of change in pain and any change in physical and psychosocial function (McDonald, 2013; Rhode Island Department of Health, 2018).

The organizational site for this project, known as the $\mathrm{CPC}$, a primary care practice that has a high prevalence of chronic pain patients, currently utilizes the NRS on all patient visits. The CPC has many patients who receive opioid and non-opioid pain management services for chronic pain. The current practice of the CPC is for the medical assistant to ask the patient their NRS during a rooming process along with vital signs. The results are recorded in the Electronic Health Record (EHR), however a baseline review of the EHR revealed that the pain score was not consistently addressed in the documentation by the provider. This was most likely a result of ineffective use of health information technology as certain screening information obtained by the medical assistant, including the pain scale, was not automatically populated into the providers' clinical documentation. 


\section{Purpose Statement and Specific Aims}

This project attempts to determine the feasibility and efficacy of using a

multidimensional pain assessment tool to evaluate chronic pain in a primary care setting.

The specific aim of this project was to evaluate how well the PEG multidimensional pain assessment tool, which includes functional status and quality of life measures compares to the unidimensional, NRS which measures pain intensity alone. The efficacy of using the PEG in a primary care setting to assess chronic pain was evaluated. Also, the project sought to evaluate how the use of the PEG, in comparison to the NRS, impacts pain management decisions.

\section{Conceptual/Theoretical Framework}

Dunn's middle-range theory of Adaptation to Chronic Pain (ACP) was the theoretical basis for this project (Dunn, 2004, 2005). The ADP was deduced from Roy's adaptation model (Roy \& Andrews, 1999), a grand nursing theory. Middle range theories are useful for advanced nursing clinical practice and clinical research as they are explanatory and chosen for their applicability to the specific patient population or setting. The ACP and Roy's adaptation model both promote a comprehensive and individualized approach to pain assessment and management.

The ACP looks at the contextual variables that impact the patient's experience of pain and affect their coping strategies. Dunn found a statistically significant indirect relationship between pain intensity, functional ability, and depressive symptoms (Dunn, 2004). These are all factors evaluated in this project using the PEG scale. The ACP has significance in how nurses and providers assess and manage patients having chronic pain. This model fits well with the DNP project utilizing the PEG to assess not only the 
patient's pain, but also the impact of pain on enjoyment of life and general activity. A

Logic Model (Appendix E.) was developed to guide this quality improvement project.

\section{Methods}

This quality improvement project used a comparative design as well as a retrospective chart review. Both the NRS and PEG assessment scales were utilized for each participant. The nurse practitioner (NP) conducting the office visit administered the pain scales verbally to the patient, recording the results in the Electronic Health Record (EHR). Data collection consisted of the NRS from the current visit and from the two most recent previous office visits, as well as the PEG score from the current visit. Review of the EHR was done to obtain the baseline data of pain management strategies that had been recommended and/or utilized during the visits in which the NRS alone was used.

\section{Setting}

This project was conducted at the Rhode Island Hospital Center for Primary Care (CPC) located in an urban, inner-city section of Providence, Rhode Island. The CPC is part of an academic teaching center, affiliated with Brown University Medical School. The CPC serves more than 12,000 patients per year. The patient population is largely low-income with more than $80 \%$ of patients being under- or uninsured. The CPC is a Patient Centered Medical Home, a designation by the Agency for Healthcare Research and Quality (AHRQ) based upon a comprehensive model of primary health care (Agency for Healthcare Research and Quality, 2012). During a six-month survey of CPC office visits in 2019 , approximately $25 \%$ of the patients had a diagnosis of chronic pain. 


\section{Participants}

The 25 participants, all established patients of the CPC, consisted of 14 males and 11 females. They were recruited using rolling enrollment at the time of their scheduled appointment with a nurse practitioner (NP). All participants met criteria of having chronic pain, defined as lasting a minimum of three months. One participant had chronic pain for one year, the others had chronic pain for greater than three years. The participants ranged in age from 49 to 80 years old with an average age of 64 (median 62). Back pain was the most prevalent pain diagnosis (56\%), followed by arthritis $(20 \%)$, fibromyalgia (8\%), peripheral vascular disease $(8 \%)$, and neuropathy $(8 \%)$. Forty percent of the participants had more than one source of pain and were classified under their primary complaint. Inclusion criteria were ability to provide informed consent and ability to verbally respond to the three PEG scale questions. Non-English-speaking patients were excluded as the PEG has not yet been validated in other languages.

\section{Intervention}

During a routine scheduled nurse practitioner (NP) visit, the medical assistant obtained the NRS according to the CPC routine practice. The NP then obtained written informed consent from the patient, verified the NRS score, followed by an assessment using the PEG scale. A"Smart Phrase," was created so that the provider was able to incorporate the documentation of the PEG score directly into the clinical office visit note. The remainder of the office visit continued as usual with documentation in the Electronic Health Record (EHR). 


\section{Measures}

Data collection consisted of the NRS from the current visit and from the two most recent previous office visits, as well as the PEG score from the current visit. Review of the EHR was done to obtain baseline data of pain management strategies that had been utilized during the prior two visits during which the NRS alone was used. The pain management included strategies, such as medications, physical therapy, cortisone injections, chiropractic treatment, behavioral health modalities and visits with specialists, such as orthopedic or spine specialists. Health care services for pain were classified using pain treatment indicators according to the National Pain Strategy using the categories of medications, professional services, procedures and miscellaneous non-pharmacologic measures (Interagency Pain Research Coordinating Committee, 2016) (See Appendix C).

\section{Analysis}

Comparative analysis using a t-test was conducted to determine if there was a significant difference between the NRS and the PEG scale scores. The t-test was used to compare the values of the mean PEG score to the NRS for each participant, as well as a separate comparison between the NRS and the P (Pain), the E (Enjoyment) and the G (General Activity) score. . . A comparison was made of the pain management modalities at baseline with use of the NRS with the pain management modalities ordered or recommended based upon the PEG assessment.

\section{Ethical Considerations}

Institutional Review Board approval was obtained from both Lifespan (Rhode Island Hospital) and from Rhode Island College. Informed written consent was obtained from 
all participants (Appendix F.). Privacy was provided during all interactions with the participants, which took place in an exam room... Participation was voluntary, no treatment was withheld and there were no risks associated with the intervention. Measures were taken to declassify data, to report it only in aggregate form, and to protect electronic data from possible breach. The primary researcher and primary investigator have no disclosures and no costs were incurred.

\section{Results}

The PEG score is obtained by adding the score for the P (Pain), E (Enjoyment of life), and G (General activity), then dividing the total by three. The PEG score was plotted against the contemporaneous NRS score for each patient (Figure 2).. . There was a visible, but not significant, increase in PEG scores with higher NRS scores with a correlation coefficient of $0.22892610, t=1.12784221$. Next, each separate component of the PEG score (the P, the E, and the G score) was plotted against the contemporaneous NRS for each patient. The P element of the PEG score was plotted as a function of the NRS score with a correlation coefficient of 0.15005223 and $t=0.72786607$ which is not significant. Likewise, there was no significant correlation between the E or G of the PEG score when plotted against the NRS. 
Figure 2. PEG versus Contemporaneous NRS

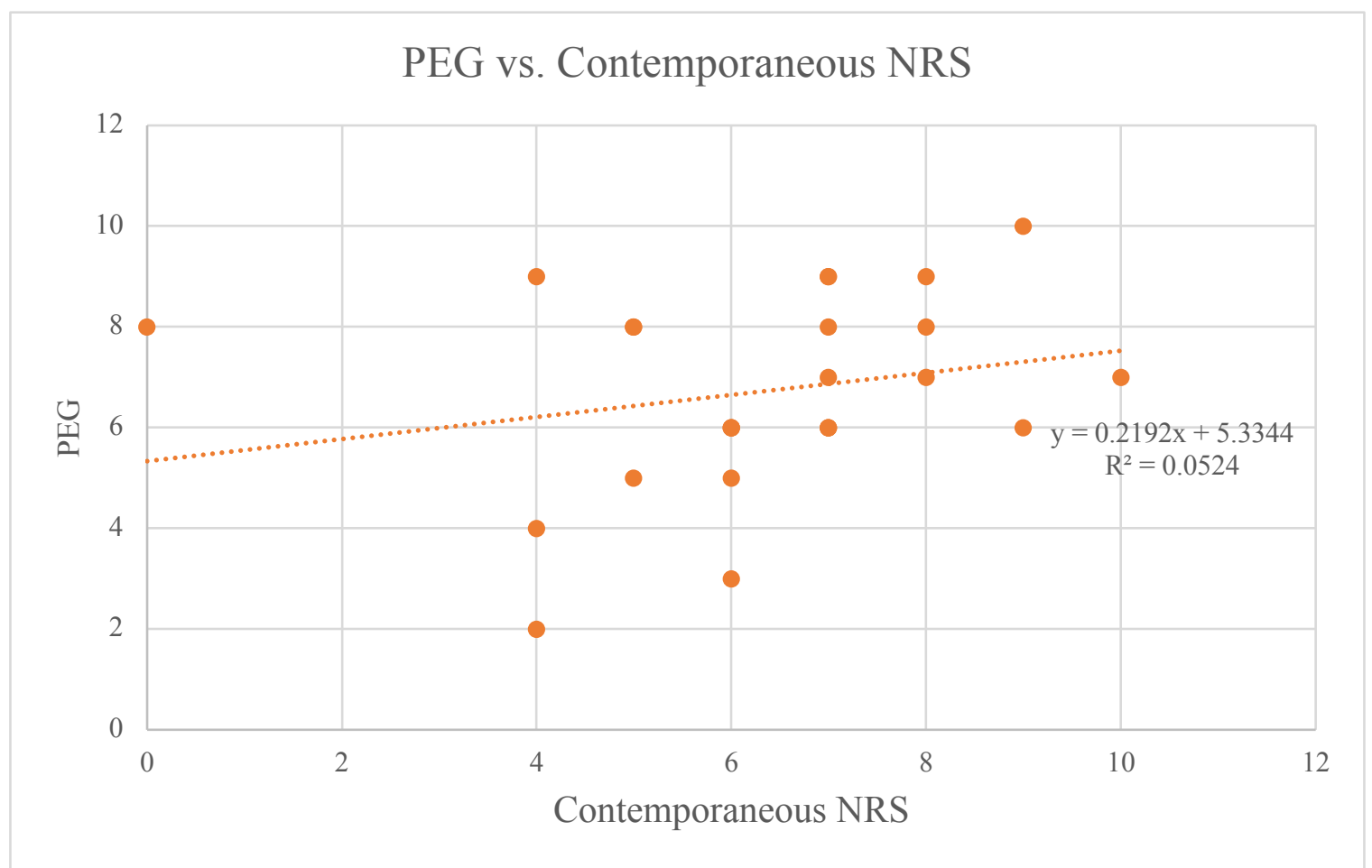

Using the coded pain management identifiers from Appendix A, each patient's current use of pain management strategies at baseline and those recommended after the PEG assessment were graphed (Figure 3). The participants used an average of 2.6 different types of medications for pain at baseline, which included adjuvant medications such as anti-depressants or anti-convulsant medications prescribed specifically for pain. At baseline, $72 \%$ of the participants were prescribed opioid pain medications. Nonpharmacologic pain management was utilized to a lesser degree than pharmacologic management at baseline. During the past year, 20\% had received physical therapy, 32\% had seen a specialist (orthopedic, neurosurgical, or pain management provider), and $24 \%$ had received either a cortisone or epidural injection for pain. 
Figure 3 Coded Pain Management Strategies

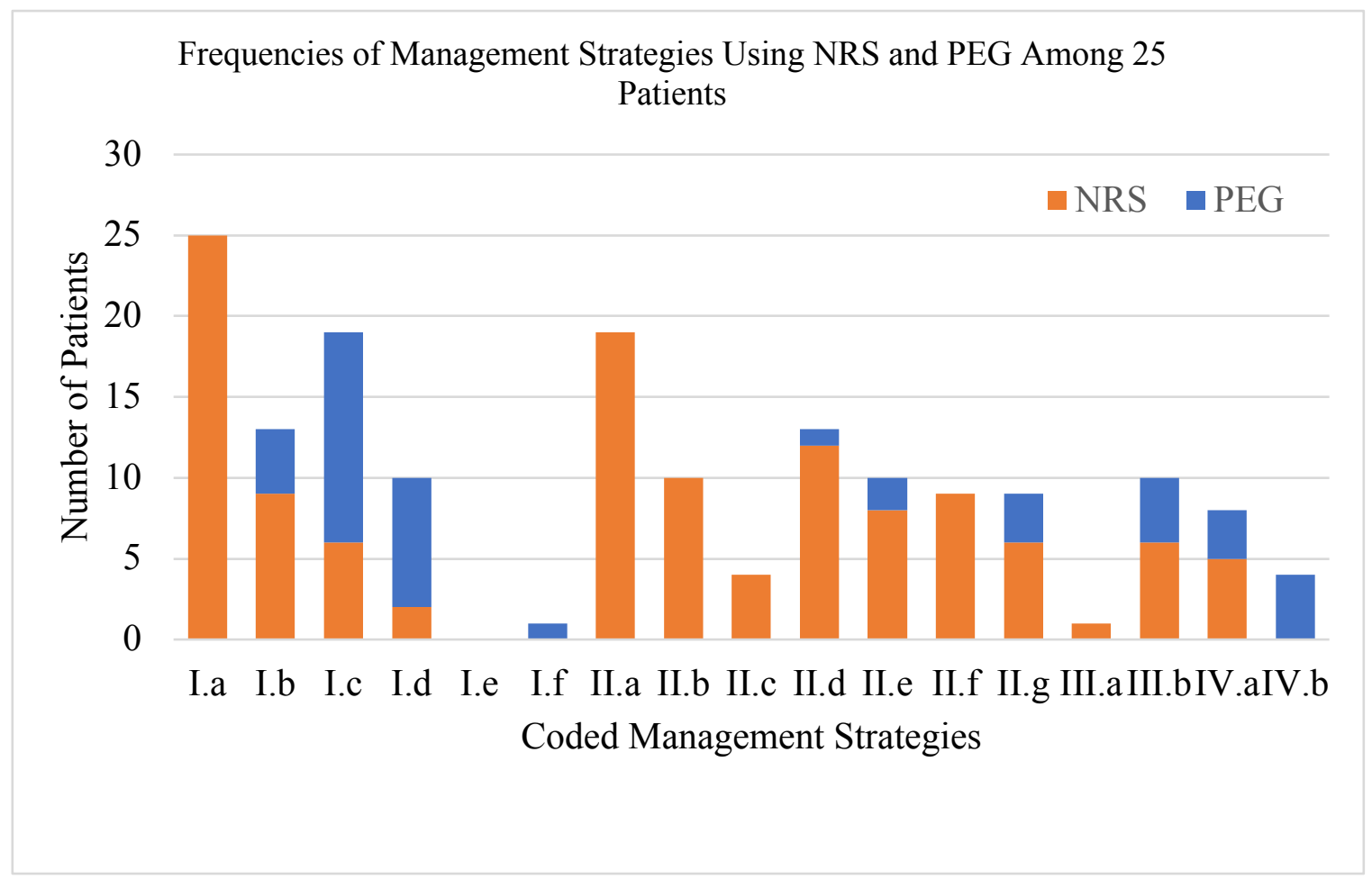

After the PEG assessment, $88 \%$ of the participants received new pain management recommendations. On average, participants received 1.7 new pain management recommendations during the visit using the PEG assessment. The addition or renewal of non-pharmacologic pain management were recommended to 23 of 25 of the participants based upon the PEG assessment. The most common non-pharmacologic modality recommended was physical therapy (52\%) and behavioral health (32\%). Sixteen percent received new referrals to an orthopedic or pain specialist specifically for a cortisone injection or nerve block.

There were no new opioid prescriptions based upon the assessment with the PEG scale. The only new pharmacologic recommendations were for topical analgesics $(12 \%)$, acetaminophen (8\%), and the anticonvulsant gabapentin (4\%). Although not typically 
considered to be a pain management modality, assistive devices such as canes, walkers, braces; and the use of home care services were included in the data collection. Twenty percent of the participants used an assistive device at baseline and an additional $16 \%$ were recommended to use an assistive device, brace or splint based upon the PEG assessment. Sixteen percent of participants were recommended to receive home care services, specifically to assist with limitations in "G" General Activity based upon the PEG assessment.

\section{Discussion}

The purpose of this quality improvement project was to evaluate the use of the PEG, a 3item multidimensional pain assessment tool, compared to the NRS unidimensional tool. The findings highlight the usefulness of the PEG assessment in providing broader, more meaningful information compared to the NRS, which measures pain intensity alone. Although one might expect the pain component of the PEG to track closely to the NRS, there was not a significant relationship between them. This finding may be explained by the fact that the PEG assessment asks about "pain on average in the past seven days", while the NRS asks about "pain right now." An example of that was one participant, an outlier on the graph, whose PEG score was eight but whose NRS score was zero. This participant explained that her "pain right now" was zero because she had received a cortisone joint injection on the day prior, however during the past seven days the pain score had been eight. Another participant who had a low NRS score but higher "P" score on the PEG explained that the "pain right now" was low because she was sitting but that the "pain on average in the past seven days" was higher because the pain increases with 
activity. These responses validate the importance and usefulness of a more comprehensive evaluation when assessing chronic pain.

The most compelling finding was that there was a great deal of variability in the PEG scores that is not "explained by" the NRS score. This reflects the fact that PEG scores are affected by factors that are not accounted for in the NRS scores. While the NRS only assesses pain intensity, the PEG assessment provides a comprehensive assessment of pain and the impact of pain on enjoyment of life and general activity. The results show variability between participants, which attests to the highly individualized nature of chronic pain and how it impacts lives.

The information provided by the PEG assessment led to an increase in multimodal pain management recommendations, which is consistent with the goals of chronic pain management (Simon, 2012). The PEG specifically asks about the impact of pain on functional status and quality of life. This assessment provides information that can facilitate more individualized and targeted management for the patient with chronic pain. By including assessments of the impact of pain on enjoyment of life and general activity, the provider was able to make recommendations, such as for physical therapy and behavioral health therapy, that may not have been identified by the NRS alone. Another added benefit from this project was that by using a "Smart Phrase," the provider was able to incorporate the documentation of the PEG score directly into the clinical office visit note. This measure led to efficiency, as well as increased the visibility of the pain assessment, which in turn increased the likelihood that it would impact patient management. 
Although the present results clearly support the benefits of using the PEG compared to the NRS, it is appropriate to recognize several potential limitations, which include the small sample size. Another limitation is that the PEG scale was only used during one office visit. The original plan of the project was to assess the participants for two to three office visits using the PEG, however that did not occur due to the COVID-19 pandemic, which interrupted the project. A longer study would be beneficial in determining if the PEG scores decrease over time because of more targeted pain management strategies. Another limitation was that only one provider, the principal researcher, utilized the PEG scale and conducted the office visit, which could introduce the possibility of performance bias.

The participants were all English speaking, having chronic pain for over one year, and the majority were on opioid pain medications. These factors limit the generalizability of the research findings. A replicated study with a broader patient population would be useful in providing more generalizable information about this topic.

\section{Sustainability and Scalability}

Sustainability for this project and the continued use of the PEG scale in assessing chronic pain has been strengthened by support at the provider level and organizational level, as well as by state and federal standards. Infrastructure measures to increase sustainability were undertaken, including the development of a "Smart Phrase," which easily places the PEG assessment tool into the EHR along with documentation of the PEG score. Future plans that would further increase sustainability include the development of a template for chronic pain documentation that would include the PEG scale, identifying treatment objectives, and more details about pain management, such as specific monitoring for 
patients on opioids. Generalizability would be achieved be reproducing this quality improvement project in a larger patient population with multiple providers and to include non-English-speaking participants. The use of the PEG scale could easily be scaled to other demographic settings and a broader population of chronic pain patients.

Although these results support the applicability of the PEG scale, the most important contribution of these findings may be that they raise a variety of intriguing questions for future study. In particular, it would be interesting to research the use of the PEG scale at earlier phases of chronic pain, for example of three to six month duration, compared to those of well-established chronic pain, to determine if it may have a greater impact on pain management and patient outcomes. While notable that $72 \%$ of this study population were already on chronic opioid pain medications, it would be of interest to research the use of the PEG scale in a chronic pain population who were not on opioids to determine how the information gathered from the PEG may influence pain management decisions.

Another area for further research would be the influence of the use of the PEG on patients' acceptance of treatment recommendations. It was noted that in this project, of the 12 participants who were advised to have physical therapy as part of their pain management, nine declined. Further study over a longer period may have different outcomes, as the provider could compare the PEG score over time and possibly use motivational interviewing techniques to encourage non-pharmacologic self-management of pain. This concurs with the 2019 TJC Standards which call for providers to involve the patient in the "pain management treatment planning process...developing realistic expectations and measurable goals that are understood by the patient for the degree, 
duration, and reduction of pain ...providing education on pain management, treatment options..." (Joint Commission, 2018).

\section{Conclusion}

Much work remains to be done to have a more complete understanding of the extent to which the use of multidimensional pain assessment instruments may impact and improve chronic pain management. It is evident that pain intensity ratings alone are inadequate, and that evaluation of functional outcomes and quality of life measures provide a richer assessment with the potential for improving pain management. Safe and effective pain management, which includes both pharmacologic and non-pharmacologic modalities, are best guided by a multidimensional pain scale, such as the PEG.

Appropriate assessment of chronic pain is the first step towards reducing the impact of pain, which would have the potential for the improvement the lives of individuals and families, as well as benefits to society. 


\section{References}

Aasvang, E., \& Kehlet, H. (1986). Classification of chronic pain. Descriptions of chronic pain syndromes and definitions of pain terms. Prepared by the International Association for the Study of Pain, Subcommittee on Taxonomy. Pain Suppl, 3, S1-S226.

Agency for Healthcare Research and Quality. (2012). Patient Centered Medical Home Resource Center: Defining the PCMH.

Anderson, D., Wang, S., \& Zlateva, I. (2012). Comprehensive assessment of chronic pain management in primary care: a first phase of a quality improvement initiative at a multisite Community Health Center. Quality in primary care, 20(6).

Bačkonja, M. M., \& Farrar, J. T. (2015). Are pain ratings irrelevant? Pain Medicine, 16(7), 1247-1250.

Buckenmaier III, C. C., Galloway, K. T., Polomano, R. C., McDuffie, M., Kwon, N., \& Gallagher, R. M. (2013). Preliminary validation of the Defense and Veterans Pain Rating Scale (DVPRS) in a military population. Pain Medicine, 14(1), 110-123.

Busse, J. W., Craigie, S., Juurlink, D. N., Buckley, D. N., Wang, L., Couban, R. J., ... \& Cull, C. (2017). Guideline for opioid therapy and chronic noncancer pain. Cmaj, 189(18), E659.

Centers for Disease Control and Prevention. (2016). Guideline for prescribing opioids for chronic pain. Journal of pain \& palliative care pharmacotherapy, 30(2), 138-140.

Centers for Disease Control and Prevention. 2018 Annual Surveillance Report of Drug$\underline{\text { Related Risks and Outcomes United States. Surveillance Special Report 2pdf }}$ 
icon. Centers for Disease Control and Prevention, U.S. Department of Health and Human Services. Published August 31, 2018.

Dahlhamer, J., Lucas, J., Zelaya, C., Nahin, R., Mackey, S., DeBar, L., ... \& Helmick, C. (2018). Prevalence of chronic pain and high-impact chronic pain among adultsUnited States, 2016. Morbidity and Mortality Weekly Report, 67(36), 1001.

Dowell, D., Haegerich, T. M., \& Chou, R. (2016). CDC guideline for prescribing opioids for chronic pain-United States, 2016. Jama, 315(15), 1624-1645.Dunn, K. S. (2004). Toward a middle-range theory of adaptation to chronic pain. Nursing Science Quarterly, 17(1), 78-84.

Dunn, K. S. (2005). Testing a middle-range theoretical model of adaptation to chronic pain. Nursing science quarterly, 18(2), 146-156.

Goldsmith, E. S., Taylor, B. C., Greer, N., Murdoch, M., MacDonald, R., McKenzie, L., ... \& Wilt, T. J. (2018). Focused evidence review: psychometric properties of patient-reported outcome measures for chronic musculoskeletal pain. Journal of general internal medicine, 33(1), 61-70.

Interagency Pain Research Coordinating Committee (2011). IPRCC Federal Pain Research Portfolio Analysis Report.

Interagency Pain Research Coordinating Committee. (2016). National pain strategy.

Jensen, M. P. (2003). The validity and reliability of pain measures for use in clinical trials in adults: review paper written for the initiative on methods, measurement, and pain assessment in clinical trials (IMMPACT) meeting, April 12-13 2003.

Jimenez, S. L. (1996). Pain \& comfort: Establishing a common vocabulary for exploring issues of pain and comfort. The Journal of Perinatal Education, 5(4), 53-57. 
Joint Commission. (2014). Joint Commission Perspectives.

Joint Commission. (2018). R3 Report Issue 11: Pain assessment and management standards for hospitals.

Katz, J., Rosenbloom, B. N., \& Fashler, S. (2015). Chronic pain, psychopathology, and DSM-5 somatic symptom disorder. The Canadian Journal of Psychiatry, 60(4), $160-167$.

Krebs, E. E., Lorenz, K. A., Bair, M. J., Damush, T. M., Wu, J., Sutherland, J. M., ... \& Kroenke, K. (2009). Development and initial validation of the PEG, a three-item scale assessing pain intensity and interference. Journal of general internal medicine, 24(6), 733-738.

Krebs EE, Bair MJ, Damush TM, Tu W, Wu J, Kroenke K. (2010). Comparative responsiveness of pain outcome measures among primary care patients with musculoskeletal pain. Medical Care, 48(11):1007-1014. doi:10.1097/MLR.0b013e3181eaf835.

Lu, S. (2015, November). A new national pain strategy. Monitor on Psychology, 46(10). http://www.apa.org/monitor/2015/11/sidebar-pain

Mackey, S. (2014). National pain strategy task force: the strategic plan for the IOM pain report. Pain Medicine, 15(7), 1070-1071.

McCaffery, M. (1968). Nursing practice theories related to cognition, bodily pain, and man-environment interactions. University of California Print. Office.

McDonald, J. V. (2013). Opioid prescribing: guidelines, laws, rules, regulations, policies, best practices. Rhode Island Medical Journal, 96(11), 38. 
Moore, B. A., Anderson, D., Dorflinger, L., Zlateva, I., Lee, A., Gilliam, W., ... \& Kerns, R. D. (2016). Stepped care model for pain management and quality of pain care in long-term opioid therapy. Journal of Rehabilitation Research \& Development, 53(1).

National Institutes of Health. (2019). Pain management best practices interagency task force report. NIH. Retrieved from: https://www.hhs.gov/about/news/2019/05/30/pain-management-task-forceissues-final-report-on-best-practices-for-treatment-of-pain.html?

Pain Management, Opioid Use and Registration of Distributors of Controlled Substances in Rhode Island. Rhode Island Department of Health Accessible https://risos-apaproduction public.s3.amazonaws.com/DOH/REG_9702_20180806190700.pdf

Phillips DM. JCAHO pain management standards are unveiled. Joint Commission on Accreditation of Healthcare Organizations. JAMA. 2000; 284(4):428-9.

Reuben, D. B., Alvanzo, A. A., Ashikaga, T., Bogat, G. A., Callahan, C. M., Ruffing, V., \& Steffens, D. C. (2015). National Institutes of Health Pathways to Prevention Workshop: the role of opioids in the treatment of chronic pain. Annals of internal medicine, 162(4), 295-300.

Roy, C., \& Andrews, H. A. (Eds.). (1999). The Roy adaptation model. Prentice Hall. Rules and Regulations for Pain Management, Opioid Use and The Registration of Distributors of Controlled Substances in Rhode Island. 2015. http://sos.ri.gov/documents/archives/regdocs/released/pdf/DOH/8003.pdf.

Simon, L. S. (2012). Relieving pain in America: A blueprint for transforming prevention, care, education, and research. Journal of pain \& palliative care 
pharmacotherapy, 26(2), 197-198.Stevens, J. E. (2019). Implementation of a Chronic Pain Functional Assessment Tool in Primary Care Practice.

Torrance, N., Smith, B. H., Elliott, A. M., Campbell, S. E., Chambers, W. A., Hannaford, P. C., \& Johnston, M. (2011). Potential pain management programmes in primary care. A UK-wide questionnaire and Delphi survey of experts. Family practice, 28(1), 41-48.

Treede, R. D., Rief, W., Barke, A., Aziz, Q., Bennett, M. I., Benoliel, R., ... \& Giamberardino, M. A. (2019). Chronic pain as a symptom or a disease: the IASP Classification of Chronic Pain for the International Classification of Diseases (ICD-11). Pain, 160(1), 19-27.

Younger, J., McCue, R., \& Mackey, S. (2009). Pain outcomes: a brief review of instruments and techniques. Current pain and headache reports, 13(1), 39-43. 


\section{Appendices}

Appendix A. Health care services for pain classified using pain treatment indicators (National Pain Strategy, 2018)

\begin{tabular}{|c|c|c|}
\hline Type of Service & Code & Sub-types \\
\hline \multirow{6}{*}{ Professional Services } & I.a. & Primary care visits \\
\hline & I.b. & $\begin{array}{l}\text { Pain specialist visits (orthopedic, } \\
\text { rheumatology, neurosurgery, rehabilitation } \\
\text { medicine) }\end{array}$ \\
\hline & I.c. & Physical therapy visits \\
\hline & I.d. & Psychology/behavioral health visits \\
\hline & I.e. & Chiropractic visits \\
\hline & I.f. & Alternative/complementary care visits \\
\hline \multirow{7}{*}{ Oral medications } & II.a. & Opiods \\
\hline & II.b. & NSAIDs \\
\hline & II.c. & $\begin{array}{l}\text { Sedatives, anxiolytics, sleep medications, } \\
\text { muscle relaxants }\end{array}$ \\
\hline & II.d. & Anticonvulsants \\
\hline & II.e. & Antidepressants \\
\hline & II.f. & Acetaminophen \\
\hline & II.g. & Topical analgesic \\
\hline \multirow{2}{*}{ Procedures } & III.a. & Surgery \\
\hline & III.b. & Injections, blocks, infusions \\
\hline \multirow{2}{*}{ Miscellaneous } & IV.a. & Assistive device, brace, walker, cane, splint \\
\hline & IV.b. & Home health services \\
\hline
\end{tabular}


Appendix B. Timeline

\begin{tabular}{l|l} 
May 2019 & DNP Project Proposal-Poster Presentation \\
\hline Summer 2019 & Development of Project Methodology \\
\hline February 10, 2020 & Lifespan (RI Hospital) IRB application approved \\
\hline $\begin{array}{l}\text { February 29, 2020 } \\
\text { February 28- } \\
\text { March 30, 2020 }\end{array}$ & Enrollment, project implementation and data collection \\
\hline $\begin{array}{l}\text { April 1 - } \\
\text { April 28, 2020 }\end{array}$ & Data Analysis \\
\hline $\begin{array}{l}\text { May 12, 2020 } \\
\text { Rhode Island College Doctor of Nursing Practice Symposium }\end{array}$
\end{tabular}


Appendix C. Force Field Analysis

\begin{tabular}{|c|c|c|c|c|}
\hline Forces FOR Change & Score & Change Proposal & Forces AGAINST Change & Score \\
\hline $\begin{array}{l}\text { Change for the better: quality } \\
\text { improvement }\end{array}$ & 5 & \multirow{8}{*}{$\begin{array}{l}\text { Implement use of PEG Pain Assessment tool } \\
\text { (PEG) in place of Numeric Pain Rating Scale } \\
\text { (NPRS) in Primary Care setting for } \\
\text { assessment of chronic pain in outpatient } \\
\text { medical practice. }\end{array}$} & Changing the status quo & 3 \\
\hline $\begin{array}{l}\text { Meaningful use (Improving } \\
\text { quality, safety, efficiency, and } \\
\text { reducing health disparities) }\end{array}$ & 5 & & $\begin{array}{l}\text { Time factor ( } 3 \text { item vs } 1 \text { item } \\
\text { scale) }\end{array}$ & 3 \\
\hline Increased focus on outcomes & 5 & & Change in process (technical) & 3 \\
\hline Patient-centered care & 5 & & $\begin{array}{l}\text { Change in practice (MA, } \\
\text { providers) }\end{array}$ & 3 \\
\hline Patient satisfaction & 4 & & $\begin{array}{l}\text { Demographic factors } \\
\text { (language, health literacy) }\end{array}$ & 3 \\
\hline $\begin{array}{l}2019 \text { Joint Commission revised } \\
\text { pain assessment } \\
\text { recommendations }\end{array}$ & 5 & & $\begin{array}{l}\text { Pain as the } 5^{\text {th }} \text { vital sign } \\
\text { routine, 2001 Joint } \\
\text { Commission } \\
\text { recommendation }\end{array}$ & 2 \\
\hline $\begin{array}{l}\text { Organizational support } \\
\text { (leadership \& providers) }\end{array}$ & 4 & & $\begin{array}{l}\text { Delegation, roles, } \\
\text { accountability (MA not } \\
\text { accountable to NP proposing } \\
\text { change) }\end{array}$ & 2 \\
\hline TOTAL & 39 & & TOTAL & 19 \\
\hline
\end{tabular}


Appendix D. Sustainability Assessment

Benefits beyond helping patients: Score B

- quality of care, possible societal benefits

- improve efficiency, meaningful use, use of a "Smart Phrase"

Credibility of the benefits: Score A

- benefits to patients and staff are visible and believable

- benefits are supported by evidence and believed by stakeholders

Adaptability of improved process: Score A

- the improved process can adapt to, link with, and support other organizational changes

- usability in both paper and electronic form

- no disruption if specific individuals left the project

Effectiveness of the system to monitor progress: Score C

- need to set up measurement system to monitor progress

- need feedback system to reinforce benefits

- need on-going system to provide evidence of impact

- system is in place to communicate the results

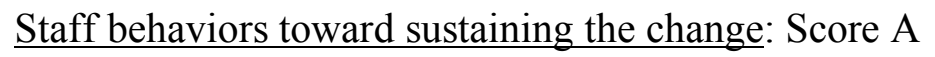

- support and involvement from staff, providers, organizational leadership

- supported by guidelines and standards (TJC, CDC)

- staff can share their ideas and believe the change is for the better 
- staff have been trained but not yet empowered to run PDSA tests

Infrastructure: Score B

- adequate facilities and equipment (Health Information Technology)

- plan for sustainability: "Smart Phrase", communication plan in place

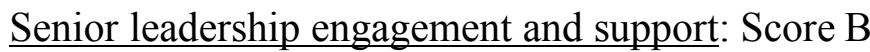

- organizational leaders are not highly involved but are moderately visible in their support of the change process

- fits with organization's strategic aims and culture 
Appendix E. Logic Model

\begin{tabular}{|c|c|c|c|c|c|}
\hline \multirow{2}{*}{ Inputs } & \multicolumn{2}{|r|}{ Outputs } & \multicolumn{3}{|c|}{ Outcomes -- Impact } \\
\hline & Activities & Participation & Short & Medium & Long \\
\hline $\begin{array}{l}\text { High prevalence of } \\
\text { chronic pain.Chronic pain } \\
\text { is associated with many } \\
\text { co-morbidities and } \\
\text { functional impact } \\
\text { The Joint Commission } \\
\text { requires the assessment of } \\
\text { pain and the right to } \\
\text { appropriate pain } \\
\text { management } \\
\text { Numeric Rating Scale } \\
\text { (NRS) unidimensional } \\
\text { pain assessment tool } \\
\text { currently used provides } \\
\text { limited information } \\
\text { 216-RICR-20-20-4.4 Pain } \\
\text { Management and Prescribing } \\
\text { "The practitioner shall obtain, } \\
\text { evaluate and document the } \\
\text { patient's health history and } \\
\text { physical examination in the } \\
\text { health record prior to treating for } \\
\text { chronic pain. Documentation of } \\
\text { Treattent...for chronic pain } \\
\text { shall state the objectives...used } \\
\text { to determine treatment } \\
\text { success..." }\end{array}$ & $\begin{array}{l}\text { PEG Pain Assessment } \\
\text { Tool } \\
\text { Data Collection of pain } \\
\text { scale scores } \\
\text { Data Collection of pain } \\
\text { management strategies } \\
\text { Data Collection of } \\
\text { Chronic pain Diagnoses } \\
\text { Patient Satisfaction } \\
\text { Survey } \\
\text { Comparison of NRS to } \\
\text { PEG Scale }\end{array}$ & $\begin{array}{l}\text { Educate NP providers } \\
\text { about PEG scale } \\
\text { Collect Data and } \\
\text { Disseminate Findings to } \\
\text { Other providers and team } \\
\text { members } \\
\text { Share information with } \\
\text { leadership }\end{array}$ & $\begin{array}{l}\text { CPC Providers will } \\
\text { demonstrate knowledge } \\
\text { and awareness of Pain } \\
\text { Assessment requirements } \\
\text { and recommendations }\end{array}$ & $\begin{array}{l}\text { CPC Providers will utilize } \\
\text { the PEG Pain Assessment } \\
\text { tool } \\
\text { CPC Providers will use } \\
\text { the PEG Pain Assessment } \\
\text { tool results to develop } \\
\text { patient-centered pain } \\
\text { management strategies }\end{array}$ & $\begin{array}{l}\text { All CPC providers will } \\
\text { use the PEG Pain } \\
\text { Assessment tool for all } \\
\text { patients having chronic } \\
\text { pain. } \\
\text { Providers will re-assess } \\
\text { improvement in pain } \\
\text { management using the } \\
\text { PEG scale } \\
\text { Patient satisfaction } \\
\text { scores will improve } \\
\text { Pain management will be } \\
\text { more multi-modal and } \\
\text { less medication-focused. }\end{array}$ \\
\hline \multicolumn{3}{|c|}{$\begin{array}{l}\text { Assumptions } \\
\text { NRS provides limited information about chronic pain. Pain assessment is required } \\
\text { but providers are not consistent in addressing chronic pain or managing effectively. } \\
\text { TJC standards for pain assessment have been blamed for triggering over- } \\
\text { prescribing of opioids for pain management } \\
\text { Patient satisfaction scores are important to leadership and administration }\end{array}$} & \multicolumn{3}{|c|}{$\begin{array}{l}\text { External Factors } \\
\text { The Joint Commission requirements for pain screening and assessment } \\
\text { Lifespan mission: "Delivering health with care Culture of safety } \\
\text { RI Department of Health Regulations regarding pain management and prescribing } \\
\text { Diversity of patient population, diversity of provide }\end{array}$} \\
\hline
\end{tabular}




\section{Appendix F. Informed Consent Form}

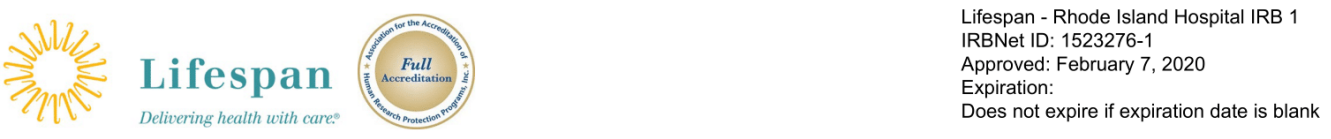

\section{Consent for Research Participation}

\section{Research Consent and Authorization Form}

Rhode Island Hospital, The Miriam Hospital, EP Bradley Hospital, Newport Hospital, and Gateway HealthCare

Name of Study Participant:

\section{Principal Investigator:}

Title of Research Study:
Joan Walsh

Implementation and Evaluation of the PEG Pain Assessment Scale in a Primary Care Setting

\section{Nature and Purpose of the Study}

The purpose of this project is to learn more about pain assessment tools to evaluate chronic pain. You are being asked to participate in this research because you have chronic pain. Currently most patients are asked to rate their pain on a scale of one to 10. That is called the Numeric Rating Scale (NRS). This has been found to work well for acute pain but maybe not as well for chronic pain. This study will use a new pain scale called the PEG Pain assessment scale as well as the NRS scale. The PEG Pain scale has three questions that you are asked to rate. In this study we want to use the PEG Pain Assessment Scale to evaluate your chronic pain and the impact of pain on your life. The study is looking at how well the PEG Pain Scale works compared to the currently used Numeric Rating Scale (NRS). We will enroll up to 50patients in this study. The study is sponsored by the Department of Ambulatory Care. No additional funds will be used.

\section{Explanation of Procedures}

If you decide to join this research study, the following things will happen:

During two of your office visits at the Center for Primary Care (CPC) the nurse practitioner (NP) will use the PEG Pain Assessment to ask you 3 questions about your pain. Your answers will consist of a number on a scale of 0 to 10 which you will report verbally to the NP. This is in addition to the usual numeric pain scale that is asked at each visit. The responses to the pain scales will be recorded in your record and on a data collection paper for this research. The rest of your office visit will proceed as usual. The researcher will review your medical record to compare the pain scale score from two previous visits which used the numeric pain scale and the two visits which use the PEG Pain Assessment. The researcher will also review your medical record to record the types of pain management that your provider recommended, such as physical therapy, medications, etc. Your medical record will be reviewed for up to six months of

Pain Assessment 01/25/20

1. 


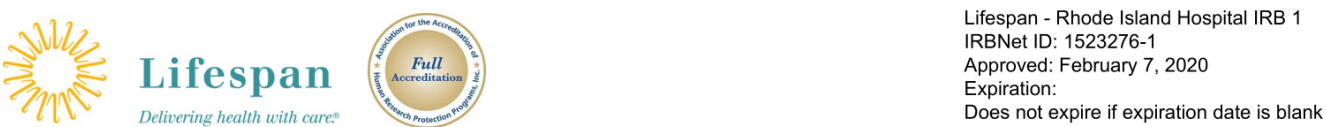

information. This would consist of the two office visit notes prior to the start of the study and two office visits during the study. The data collection will initially be recorded with your medical record number, but after all the data is collected, the medical record number will be removed and the data will be coded with an assigned number. Your identifiable health information that is collected for this study will be de-identified before any data is shared or reported. Research information will only be reported in aggregate without any personal identifiers.

Your identifiable private information may be stripped of identifiers and used for future research studies or distributed to another researcher for future research studies without additional informed consent.

\section{Contact Information:}

You can call us with any concerns or questions about the research.

Principal Investigator: Joan Walsh 401-444-5883

Principal Researcher: Nancy Harritos 401-444-4741

\section{Discomforts and Risks}

There is no discomfort or physical risk associated with the pain assessment. The risk of loss of privacy could occur if the information system were hacked - . Measures to keep your private information confidential and safe will be adhered to. This will include coding the information, storing any paper data in a locked cabinet and destroying all paper data after completion of the study. -

\section{Benefits}

You will not receive any direct benefit from your participation in this study. The most important potential benefits to know about: your provider will have a better understanding of your pain and how it affects your life. This may lead to more effective management of your chronic pain. We hope that the information we get from this study on pain assessment tools may help people with chronic pain in the future.

\section{Alternative Therapies}

You do not have to be in this research study to be treated for your chronic painful condition. Your provider will continue to evaluate you with the numeric pain scale that is currently used.

\section{Refusal/Withdrawal}

It is up to you whether you want to be in the study. You are not required to enroll or participate. If you decide to participate, you can always change your mind and quit at any time. If you decide not to be in the study, or if you quit later, you will still be able to get the health care services you normally get. If you join, but later the researcher or your doctor feels being in the study is no longer good for you, they may choose to take you out of the study before it is over.

Pain Assessment 01/25/20

total of 5 pages 


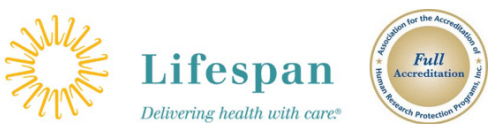

Lifespan - Rhode Island Hospital IRB 1 IRBNet ID: 1523276-1

Approved: February 7, 2020

Delivering health with cares

Expiration:

Does not expire if expiration date is blank

\section{Medical Treatment/Payment in Case of Injury - this study does not provide treatment and a treatment injury is not expected}

\section{Rights and Complaints}

Signing this form does not take away any of your lawful rights. If you have any complaints about this study or would like more facts about the rules for research studies, or the rights of people who take part in research studies, you may contact Janice Muratori in the Lifespan Office of Research Administration, at (401) 444-6246.

\section{Confidentiality and Research Authorization for Use and Disclosure of Your Health Care Information}

Your research records will be treated as private health care records and will be protected according to Lifespan privacy practices and policies that are based on state and federal law. Federal law requires us to get your permission to use or disclose (release your information to someone outside of Lifespan) your health information for research purposes. If you sign this form, you agree to be in this research study and you permit the use and disclosure of your health information for the purpose of conducting the research, providing treatment, collecting payment and running the business of the hospital. This permission has no expiration date. You may withdraw from the study at any time. However, if you do not want the researchers to use or disclose any further information in this study, you must cancel permission in writing and may do so at any time. If you cancel your permission, you will stop taking part in the study and no new information will be collected about you. However, if you cancel your permission, it will not apply to actions already taken or information already collected about you by the hospital or the researchers before you canceled your permission.

Generally, the entire research record and any medical records held by the hospital may be used and released for research purposes. The following people or businesses/companies might use, release, or receive such information:

- The researcher and their support staff;

- The study sponsor: Department of Ambulatory Care

- Doctors, nurses, laboratories and others who provide services to you or the sponsor in connection with this study;

- The company or section of the U.S. government that is paying for the study and others they hire to oversee, administer, or conduct the research;

- The United States Food and Drug Administration, the Department of Health and Human Services, the Office of Inspector General, the Office of Civil Rights, European Medicines Agency

- People who volunteer to be patient advocates or research volunteer protectors; 


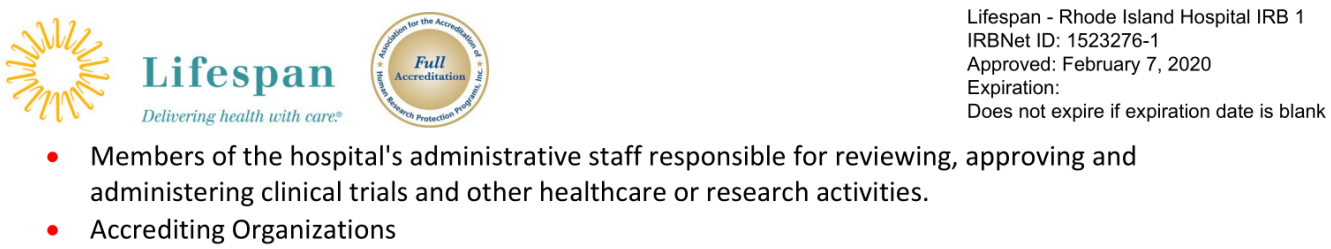

There are times when the law might require or permit Lifespan to release your health information without your permission. For example, Rhode Island law requires researchers and health care workers to report abuse or neglect of children to the Department of Children, Youth and Families (DCYF) and to report abuse or neglect of people age 60 and older to the Department of Elderly Affairs.

All researchers and health care providers are required to protect the privacy of your health care information. Other people and businesses/organizations that are not health care providers are not required by law to do that, so it is possible they might re-release your information. You have the right to refuse to sign this form and not participate in the research. Your refusal would have no effect on your treatment, charges billed to you, or benefits at any Lifespan health care site. If you do not sign, you will not be able to enroll in the research study and will not receive treatment as a study participant.

If you decide to quit the study after signing this form (as described in Section 6: Refusal/Withdrawal), no new information will be collected about you unless you gave us permission to do so. However, the hospital or the researchers may continue to use information that was collected before you quit the study to complete analysis and reports of this research. You will not be allowed to see or copy the information described in this form if the research is open. You may see and copy the information when the study is completed.

\section{SIGNATURE}

I have read this informed consent and authorization form. ALL OF MY QUESTIONS HAVE BEEN ANSWERED, AND I WANT TO TAKE PART IN THIS RESEARCH STUDY.

By signing below, I give my permission to participate in this research study and for the described uses and releases of information. I also confirm that I have been now or previously given a copy of the Lifespan Privacy Notice.

This informed consent document is approved for use with a valid IRB stamp at the top of each page. The document expires for use on the date listed within the IRB stamp. DO NOT sign this document after this expiration date.

If the expiration date is blank, this document does not expire

The Researcher is required to provide a copy of this consent to you.

Pain Assessment 01/25/20

total of 5 pages 


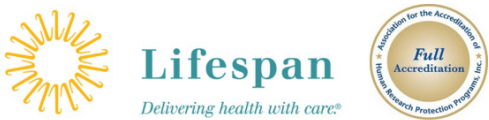

Lifespan - Rhode Island Hospital IRB 1 IRBNet ID: 1523276-1

Approved: February 7, 2020

Delivering health with cares

Expiration:

Does not expire if expiration date is blank

Signature of Adult Study Participant

Date (MM/DD/YEAR) Time when signed

Signature of researcher or designate

Date(MM/DD/YEAR) Time when signed

A copy of this complete (note total number of pages in footer) signed consent form has been given to the participant.

Pain Assessment 01/25/20

total of 5 pages 